
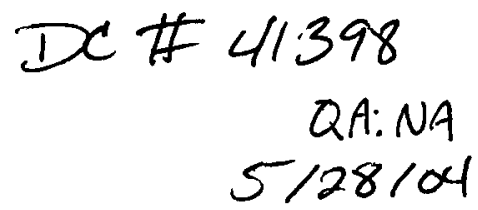

\title{
Design Concept Evaluation Using System Throughput Model
}

\author{
Gary Sequeira \\ Booz Allen Hamilton \\ 1551 Hillshire Drive \\ Las Vegas, NV 89134
}

\author{
W. Mark Nutt, Ph.D. \\ Golder Associates Inc. \\ 1551 Hillshire Drive \\ Las Vegas, NV 89134
}

\begin{abstract}
The U.S. Department of Energy (DOE) Office of Civilian Radioactive Waste Management (OCRWM) is currently developing the technical bases to support the submittal of a license application for construction of a geologic repository at Yucca Mountain, Nevada to the U.S. Nuclear Regulatory Commission. The Office of Repository Development (ORD) is responsible for developing the design of the proposed repository surface facilities for the handling of spent nuclear fuel and high level nuclear waste. Preliminary design activities are underway to sufficiently develop the repository surface facilities design for inclusion in the license application. The design continues to evolve to meet mission needs and to satisfy both regulatory and program requirements.
\end{abstract}

A system engineering approach is being used in the design process since the proposed repository facilities are dynamically linked by a series of sub-systems and complex operations. In addition, the proposed repository facility is a major system element of the overall waste management process being developed by the OCRWM. Such an approach includes iterative probabilistic dynamic simulation as an integral part of the design evolution process. A dynamic simulation tool helps to determine if:

- the mission and design requirements are complete, robust, and well integrated;

- the design solutions under development meet the design requirements and mission goals;

- opportunities exist where the system can be improved and/or optimized;

- proposed changes to the mission and design requirements have a positive or negative impact on overall system performance and if design changes may be necessary to satisfy these changes.

This paper will discuss the type of simulation employed to model the waste handling operations. It will then discuss the process being used to develop the Yucca Mountain surface facilities model. The latest simulation model and the results of the simulation and how the data were used in the design evolution process will also be discussed. Since the use of dynamic simulation is iterative and integral to the design effort, future activities will also be summarized. The paper will close discussing lessons learned from applying dynamic simulation to designing complex systems, and will discuss what pitfalls to avoid and recommendations for developing flexibility in system model development. 


\section{Introduction}

In today's world, one of the most difficult questions to answer is, "Is it going to work?" and having an answer that is technically defensible can be difficult if not impossible without the use of a system model. Models will often provide insight into how systems will operate, suggest impacts of proposed changes, and enable system concepts to be evaluated against requirements early in the development phase.

The expansion of risk-informed techniques into nuclear design through a total life-cycle approach offers the opportunity to enhance the safety while reducing both capital and operating costs (Hill 2003). They can also prove to be an effective tool in integrating the design/safety, operations, and financial sectors such that appropriate decisions are made and optimized designs are advanced. A robust and technically defensible risk-informed approach will effectively optimize the design of nuclear and non-nuclear facilities where optimization for cost competitiveness and/or safety is desired.

The Yucca Mountain Project is conducting preliminary design activities to sufficiently develop the Monitored Geologic Repository (MGR) surface facilities design for inclusion in the license application. A system engineering approach is being used in the design process since the proposed repository facilities are dynamically linked by a series of sub-systems and complex operations. In addition, the proposed repository facility is a major system element of the overall waste management process being developed by the OCRWM. Such an approach includes iterative probabilistic dynamic simulation as an integral part of the design evolution process. This is the first phase of the total life-cycle approach.

This paper describes:

- the process used to develop the initial dynamic simulation model of the proposed Yucca Mountain Project surface facilities;

- the benefits of developing a model and the types of results that can be obtained

- the lessons learned from the modeling development

- plans for subsequent modeling activities

\section{MODELING APPROACH}

The approach taken to model the MGR surface facilities began with understanding the mission requirements, the functions, the operations, and proposed design concepts. The principal objective of the MGR surface facilities dynamic simulation model was to determine throughput estimates for how much spent nuclear fuel (SNF) and high-level nuclear waste (HLW) could be processed into disposal containers in a given year. Secondary objectives included determining if various design parameters were appropriate and the identification of process constraints (e.g., bottle-necks or pinch-points). 
An example of a mission requirement is that the MGR system would be designed to process commercial SNF (CSNF) on a schedule ramp-up rate defined in Table 1 (DOE 2002).

Table 1: Yucca Mountain Commercial SNF Receipt Rates

\begin{tabular}{|c|c|}
\hline Year & $\begin{array}{c}\text { Commercial SNF } \\
\text { Receipt Rate }\end{array}$ \\
\hline 2010 & $400 \mathrm{MTHM} / \mathrm{yr}$ \\
\hline 2011 & $600 \mathrm{MTHM} / \mathrm{yr}$ \\
\hline 2012 & $1200 \mathrm{MTHM} / \mathrm{yr}$ \\
\hline 2013 & $2000 \mathrm{MTHM} / \mathrm{yr}$ \\
\hline $\begin{array}{c}2014- \\
\text { Closure }\end{array}$ & $3000 \mathrm{MTHM} / \mathrm{yr}$ \\
\hline
\end{tabular}

The modeling approach involved the following steps:

- Perform Functional Analysis and decomposition (using block flow diagrams and Material Flow diagrams)

- Allocate functions to Conceptual System Architecture

- Develop operational logic for system operation

- Using industry data and expertise estimate process times (best, nominal, and worst-case distributions)

- Analyze processes to determine if physical dependencies exist

- Develop the dynamic simulation model using the GoldSim (Golder 2003) simulation software

- Provide feedback and results to management and the design organization

- Iterate as new information becomes available and as design concepts evolve

Since the preliminary design of the facility is in its early stages and includes several first-ofa-kind systems, very little information existed to provide the technical bases for the model. The existing design information was supplemented by estimates from engineers from multiple disciplines (e.g., fuel handling, welding, operations). A facilitated approach that fostered crossdiscipline integration resulted in operational logic and process times that were felt to be reasonable.

The high level functions of the MGR surface facilities are shown in Table 2.

Table 2: MGR Surface Facilities High-Level Functions

\begin{tabular}{|c|c|c|c|c|}
\hline Transportation of Casks & $\begin{array}{c}\text { Cask } \\
\text { Receipt }\end{array}$ & $\begin{array}{c}\text { Dry Transfer } \\
\&\end{array}$ & $\begin{array}{c}\text { Welding and } \\
\text { WP Closure } \\
\text { Waste } \\
\text { Handling }\end{array}$ & Waste Emplacement \\
& & & \\
\hline
\end{tabular}


These functions were then further decomposed and allocated to Conceptual System Architecture as shown in the example on Table 3.

Table 3: Functional Decomposition and Allocation

\begin{tabular}{|c|c|}
\hline Cask Receipt Facility & Dry Transfer Facility \\
\hline $\begin{array}{l}\text { Function: Cask Acceptance } \\
\text { Process Duration: (90/150/240 Minutes) }\end{array}$ & $\begin{array}{l}\text { Function: Move/Up-Right Cask } \\
\text { Process Duration: (255/390/540 Minutes) }\end{array}$ \\
\hline $\begin{array}{ll}\text { - } & \text { Security Reviews Authorization \& } \\
\text { - Conducts Security Inspection } \\
\text { - } \quad \text { Conduct Cask Visual Inspection } \\
\text { Verify Receipt Records Comply } \\
\text { with Shipping Manifest } \\
\text { - } \quad \text { Remove Personnel Barrier } \\
\text { Conduct Radiation \& Contamination } \\
\quad \text { Survey of Carrier Vehicle }\end{array}$ & $\begin{array}{ll}\text { - } & \text { Engage Prime Mover } \\
\text { - } & \text { Move SSR/Cask from Buffer Area to } \\
& \text { Process Building } \\
\text { - } & \text { Open Exterior Airlock Door } \\
\text { - } & \text { Move SSR/Cask into Airlock } \\
\text { - } & \text { Opese Exterior Airlock Door } \\
\end{array}$ \\
\hline
\end{tabular}

In addition to understanding the MGR System Requirements, the modeling requirements were developed to ensure the dynamic simulation model would accurately simulate processes, provide user flexibility, obtain representative results of key design parameters. Examples of some of these requirements included:

1. Provide ability to evaluate variable waste stream characteristics

- Different waste types (e.g, Boiling Water Reactor (BWR), Pressurized Water Reactor (PWR)

- Waste receipt rate

- CSNF thermal characteristics (waste streams with varying average CSNF assembly thermal outputs, cooler - hotter)

2. Monitor key design parameters

- Internal CSNF staging requirements

- Thermal characteristics of loaded waste packages and aging casks

- Welding cell utilization

3. Monitor sub-process performance

- Welding cell utilization

- Fuel assembly and canister transfer crane usage

4. Monitor process "bottle-necks" or "pinch points"

5. Provide flexibility to evaluate different design options and operational scenarios:

- Different transportation modes (rail shipment verses truck)

- Types of facilities operational

- Number of process lines available

- Number of weld cells available

- Waste campaigning 


\section{Dynamic System Model Description}

The current conceptual design of the MGR surface facilities consists of

- a cask receipt building for processing transportation casks

- two dry transfer facilities (DTF 1 and DTF 2) for transferring bare and canisterized wastes into either waste packages or aging casks (AC)

- a canister handling facility (CHF) for transferring canisterized wastes into waste packages (WP)

- a facility for aging CSNF that is too hot to be emplaced in the proposed repository,

- a remediation building for processing off-normal wastes

- balance of plant facilities

The dynamic simulation model includes all of these facilities, except for the remediation building and the balance of plant facilities.

A very simplistic approach is used to thermally manage CSNF. A fuel assembly thermal output threshold is established for both BWR and PWR SNF. These thresholds can be changed. Any fuel assemblies having a thermal output above this threshold are assigned for loading into an aging canister and placed in the aging facility. Those fuel assemblies having a thermal output equal to or below this threshold are assigned for loading into a waste package for emplacement in the repository.

The overall process flow is shown in Figure 1. One of the most important components of the model is the process selection step. It is at this phase of the modeling effort that determines the logic for what processes will be performed next.

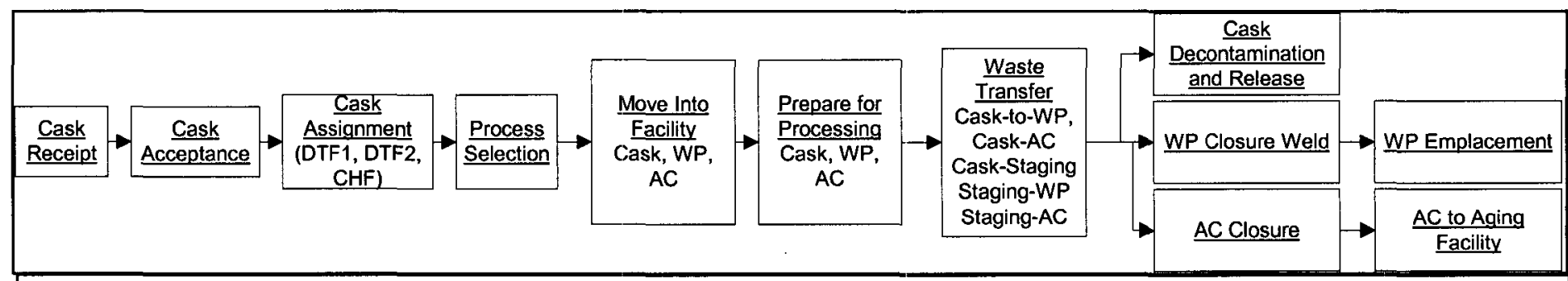

Figure 1. Yucca Mountain Surface Facility Dynamic Simulation Model General Process Flow

Identifying the exact CSNF waste stream expected to arrive at the proposed repository is not currently possible. However, the design needs to accommodate the range of CSNF waste characteristics that could potentially arrive. Thus, the model assumes a series of bounding waste streams, ranging from a cool waste stream (oldest fuel first) to a hot waste stream (youngest fuel first, aged greater than 5 years). It is assumed that the CSNF arrives randomly within a given year at rates given in Table 1. U.S. Department of Energy owned spent nuclear fuel and high level waste, 7000 MTHM in canisters, are assumed to arrive randomly over the assumed 30 year operational period. 
The cask assignment step assigns transportation casks to the DTFs and/or the CHF. If a scenario is selected where the CHF is operational, all casks containing canisterized wastes are assigned to it, else they are assigned to the DTFs. Casks containing both BWR and PWR CSNF are assigned to each DTF unless the campaign scenario is selected. In that scenario BWR CSNF is assigned to DTF1 and PWR CSNF is assigned to DTF2.

Process selection is based on three priorities, in descending order:

1. Minimize the amount of bare fuel and canisters in the staging area;

2. Maximize waste package loading;

3. Maximize aging canister loading;

4. Maximize cask processing.

Given these priorities, the following logic is evaluated to select the next processing step.

1. If there is sufficient inventory in the staging area to load a waste package, then load the waste package from the staging area alone (do not bring in a cask for processing). Else;

2. If there is sufficient inventory in the staging area to load an aging canister, then load the aging canister from the staging area alone (do not bring in a cask for processing). Else;

3. If there is sufficient inventory in the staging area and the largest available cask to load a waste package, then load a waste package from the staging area and that cask (bring in both a waste package and a cask for processing). Else;

4. If there is sufficient inventory in the staging area and the largest available cask to load an aging canister, then load an aging canister from the staging area and that cask (bring in both a waste package and a cask for processing). Else;

5. If the staging area has room to accept waste, then load the staging area from a cask. Else

6. Do nothing.

Note that in order to load a CSNF waste package, the model tracks the inventory of CSNF in both the casks and staging area with thermal output equal to or below the thermal output threshold. In order to load an aging cask, the model tracks the inventory of CSNF in both the casks and staging area with thermal output above the thermal output threshold. This is done for each waste type (BWR/PWR bare fuel and canisterized waste).

In addition to the logic steps above, the model determines whether the facility is capable of making another process selection. For example, if a cask and a waste package are being prepared for processing in a DTF, it is not possible to begin another process until those areas in the DTF have been cleared. These types of logic checks are used throughout the model to ensure proper process sequencing.

Once a selection is made, the casks, waste packages, or aging canisters are moved into the facility (either the DTFs or the CHF). They are then up-righted and moved into the preparation area. Here they are made ready for subsequent processing. From here they are moved into the hot cell and docked into the waste handling ports. 


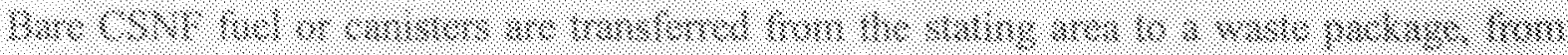

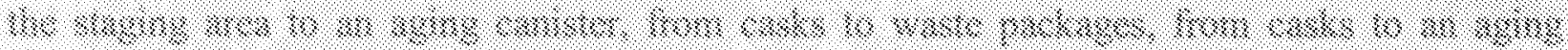

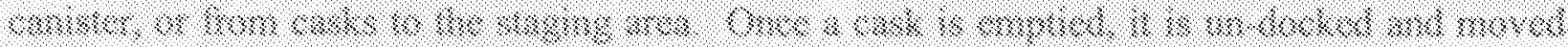

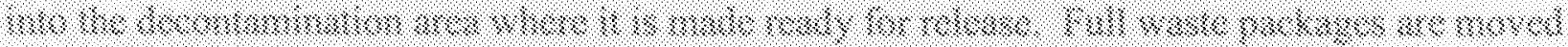

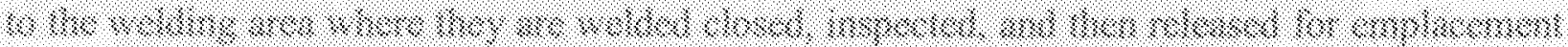

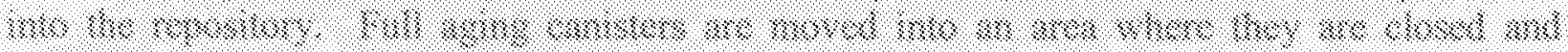

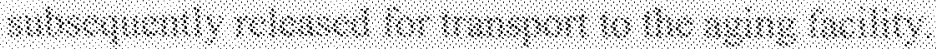

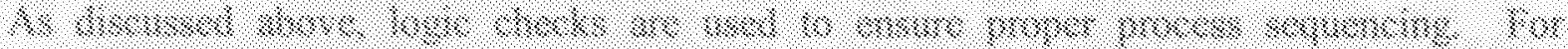

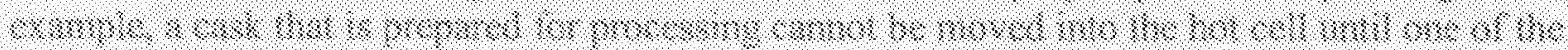

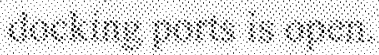

\section{Dynamic System Model Results}

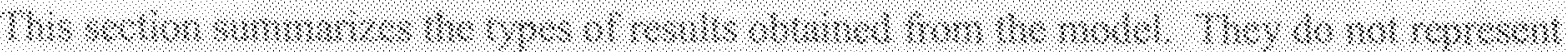

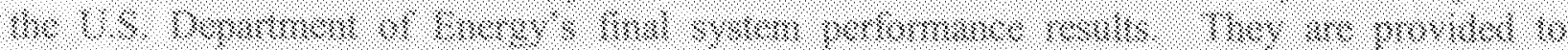

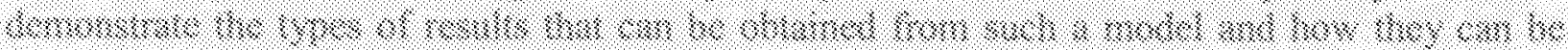

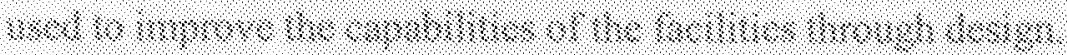

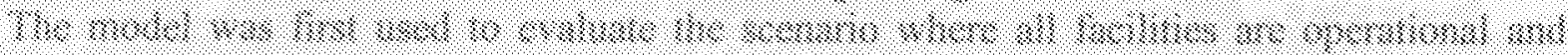

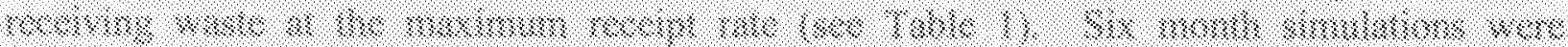

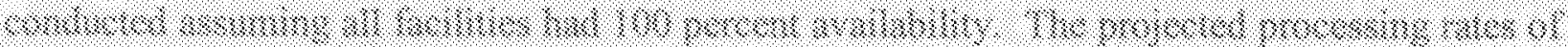

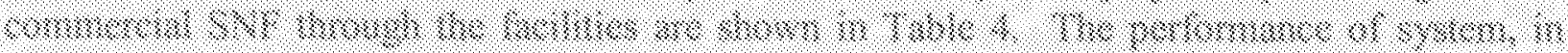

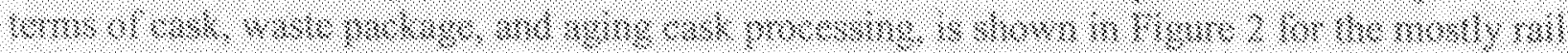

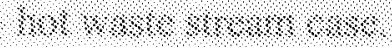

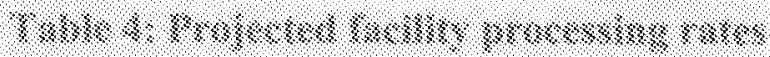

\begin{tabular}{|c|c|c|c|}
\hline 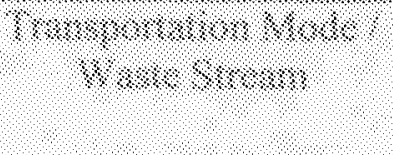 & 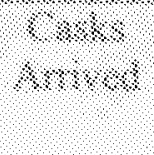 & 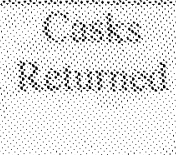 & 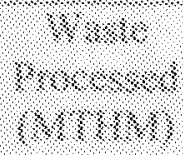 \\
\hline 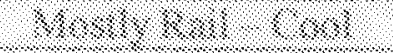 & 1018 & 1812 & 1818 \\
\hline (3) & 1818 & $1.1 \%$ & 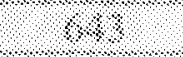 \\
\hline (1): & 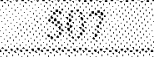 & 1118 & $4: 12$ \\
\hline 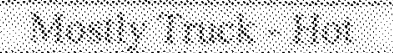 & 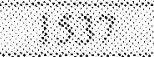 & 1818. & 1.12 \\
\hline
\end{tabular}

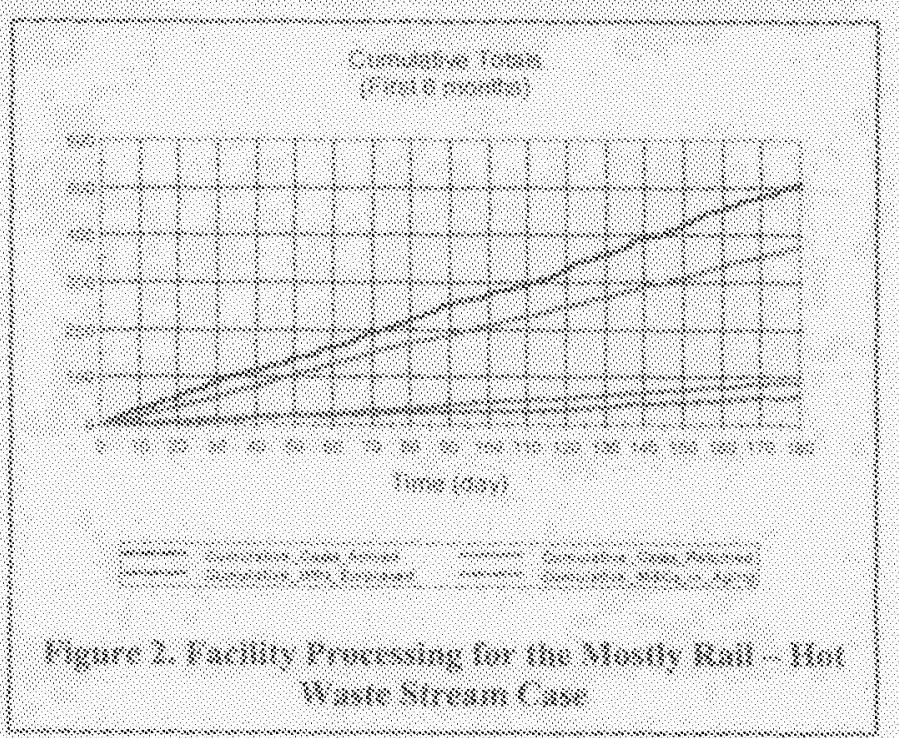


Facility processing rates largely depend on the mode by which commercial SNF is transported to the repository. Rail casks are considerably larger than truck casks. For example, the largest BWR rail cask considered in the model can transport 68 commercial SNF assemblies while the largest BWR truck cask can only transport nine. A larger number of truck casks needs to be processed through the facility in order to load an identical amount of fuel assemblies from a rail cask into either a waste package or an aging canister. Secondly, since truck casks are considerably smaller than either a waste package or an aging cask, a larger number of fuel assemblies must first be loaded into the staging area before a large enough inventory exists to load either a waste package or an aging canister. This results in more multiple handling of fuel assemblies, which lowers the processing rates.

The total amount of waste processed in six months shown in Table 1 is loaded into waste packages for the cooler waste stream. In the case of a hotter waste stream, the commercial SNF is loaded into both waste packages and aging canisters, as shown in Table 5.

Table 5: Total Six-month Commercial SNF Processing

\begin{tabular}{|c|c|c|c|}
\hline $\begin{array}{c}\text { Transportation Mode / } \\
\text { Waste Stream }\end{array}$ & $\begin{array}{c}\text { Waste } \\
\text { Processed } \\
\text { (MTHM) }\end{array}$ & $\begin{array}{c}\text { Into Waste } \\
\text { Packages } \\
\text { (MTHM) }\end{array}$ & $\begin{array}{c}\text { Into } \\
\text { Aging } \\
\text { Canisters } \\
\text { (MTHM) }\end{array}$ \\
\hline Mostly Rail - Cool & 1676 & 1676 & \\
\hline Mostly Truck - Cool & 643 & 643 & \\
\hline Mostly Rail - Hot & 1209 & 247 & 962 \\
\hline Mostly Truck - Hot & 767 & 307 & 460 \\
\hline
\end{tabular}

Tables 4 and 5 show that the thermal characteristics of the waste stream also have a significant impact on facility processing rates for the mostly rail transportation scenario. There are three factors that result in decreased processing rates for a hotter waste stream with the mostly rail transportation mode. First, it is assumed that fuel assemblies with higher thermal output must be transported in either smaller transportation casks or in transportation casks containing less than their physical capacity. As in the case of rail versus truck transportation modes for the cooler waste stream, more casks need to be processed.

Secondly, more multiple handling of fuel assemblies is required for hotter waste streams. Casks containing cooler, hotter, and a mix of cool and hot commercial SNF assemblies arrive. In order to load a waste package or an aging cask, it is necessary to place both hotter and cooler fuel assemblies into the internal staging area to build-up sufficient inventories such that a waste package or aging canister can be filled. There is less loading directly from a cask into a waste package or aging canister as is observed when loading waste packages from a cooler waste stream. This is evident in Table 6, which shows the maximum amount of BWR and PWR fuel assemblies placed in the internal staging area for the different transportation mode / waste stream scenarios. The peak internal staging inventories were determined from tracking the inventory in the staging area, shown in Figure 3 for the mostly rail - hot waste stream case. 


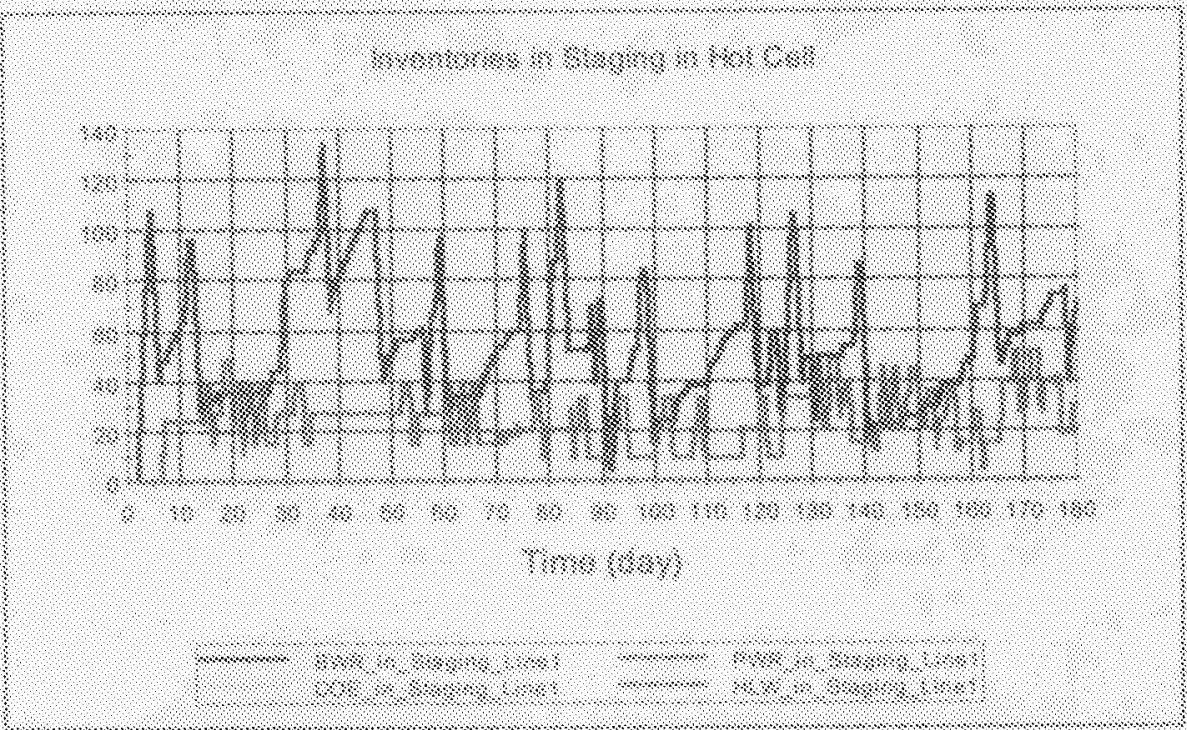

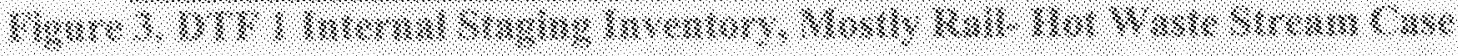

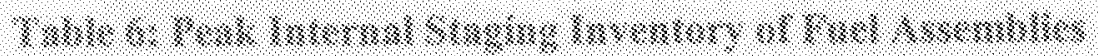

\begin{tabular}{|c|c|c|}
\hline 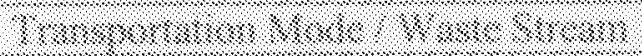 & $18: 1 \%$ & (19:18. \\
\hline 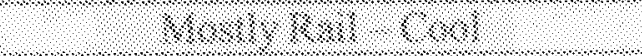 & 1918 & 18 \\
\hline 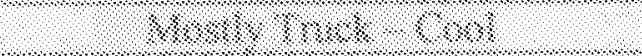 & 18. & 48 \\
\hline 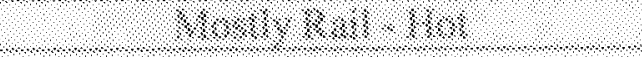 & $14: 8$ & 48 \\
\hline 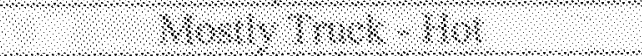 & 181.9 & 1.18 \\
\hline
\end{tabular}

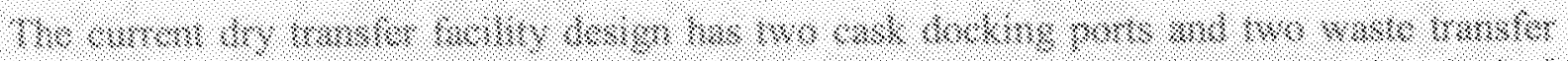

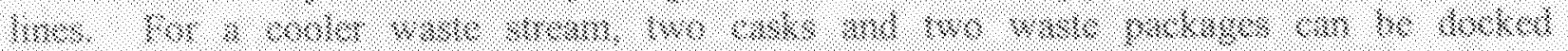

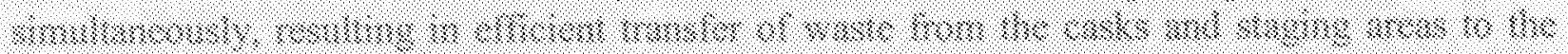

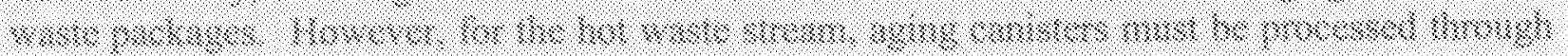

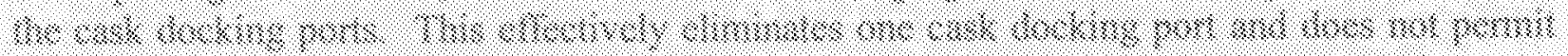

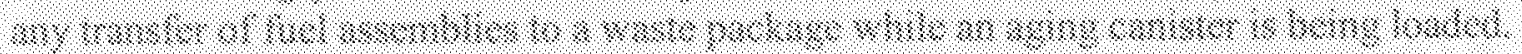

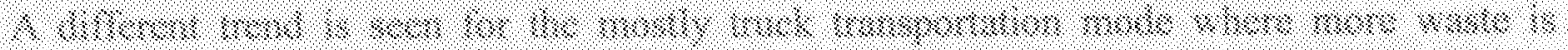

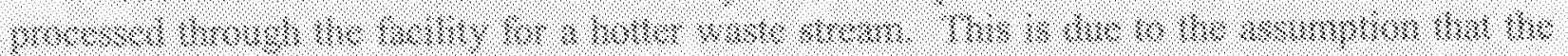

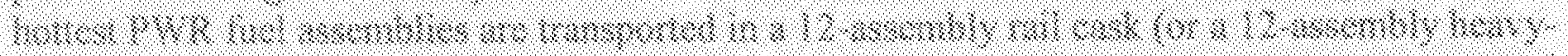

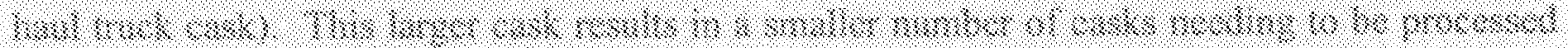

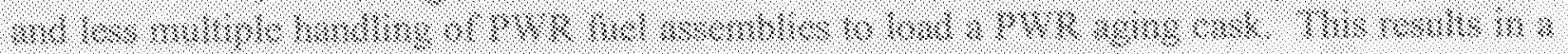

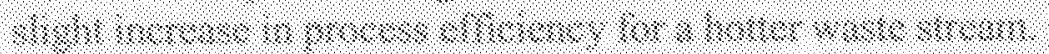

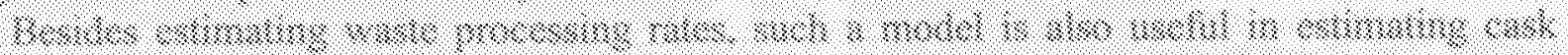

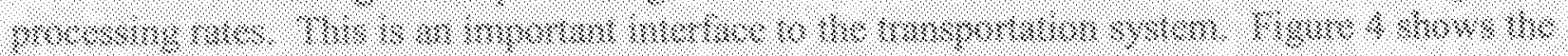

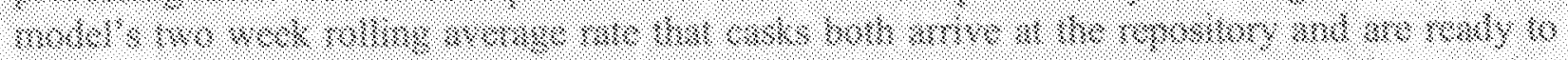

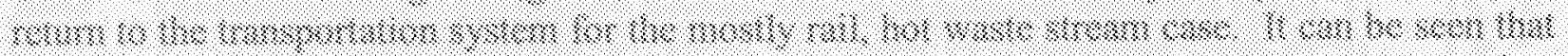

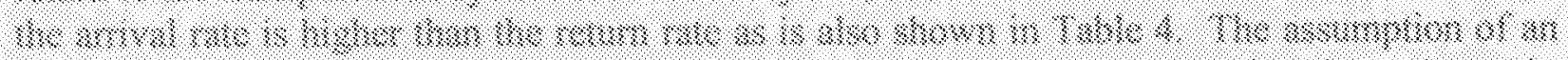

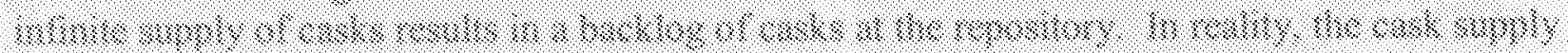

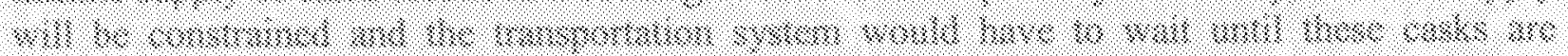

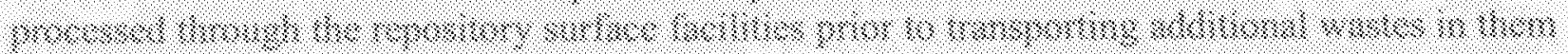

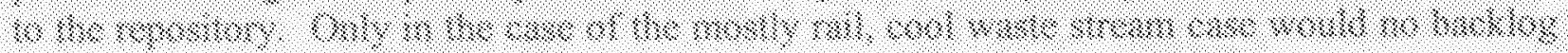




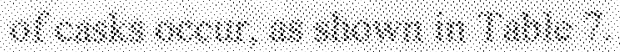

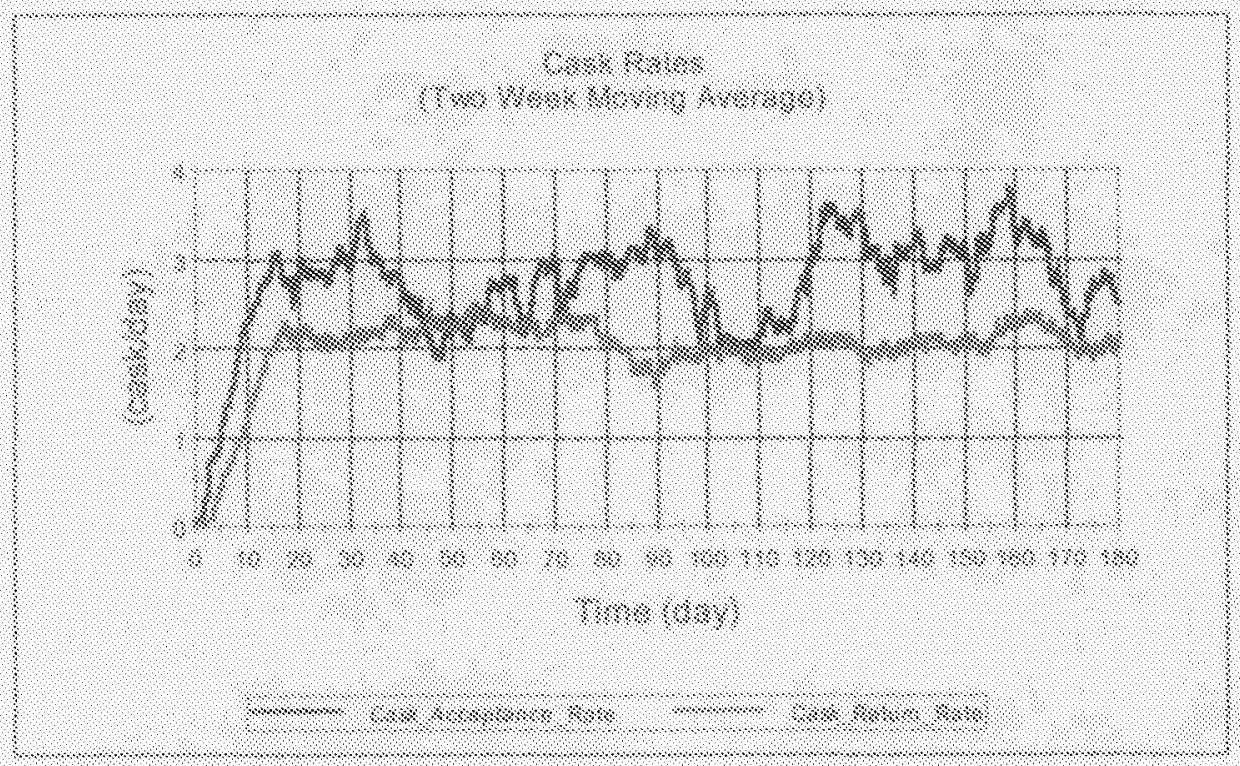

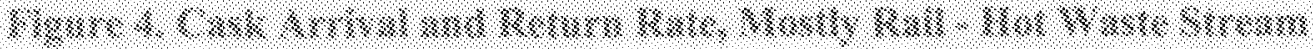

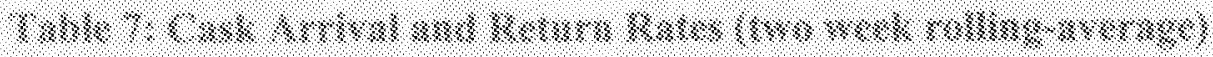

\begin{tabular}{|c|c|c|}
\hline (3) & 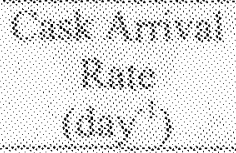 & 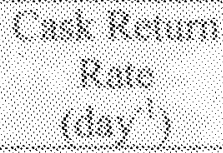 \\
\hline 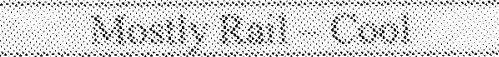 & 1411,1918 & 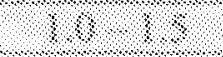 \\
\hline (1) & 1811181 & 11111818 \\
\hline 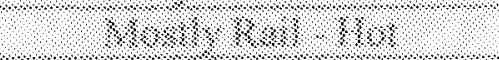 & 20.818 & 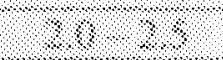 \\
\hline 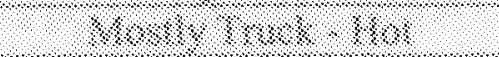 & $80 \ldots 181$ & 181.1918 \\
\hline
\end{tabular}

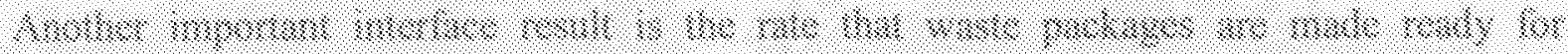

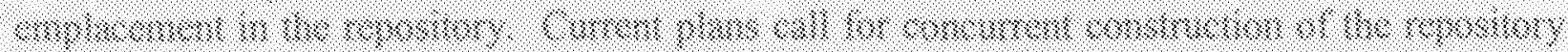

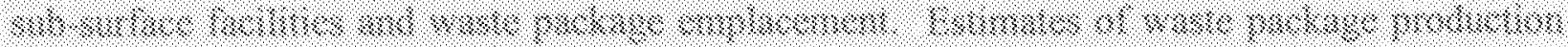

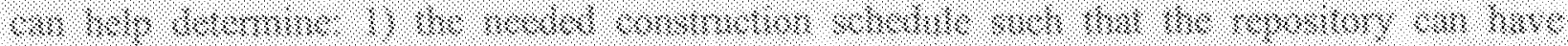

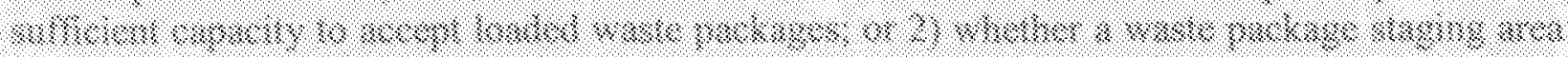

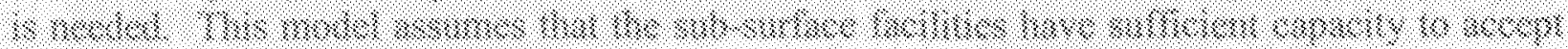

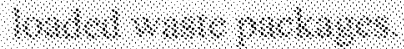

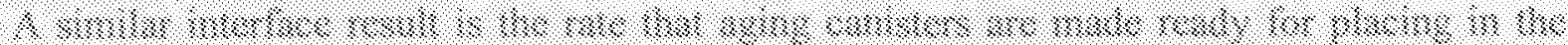

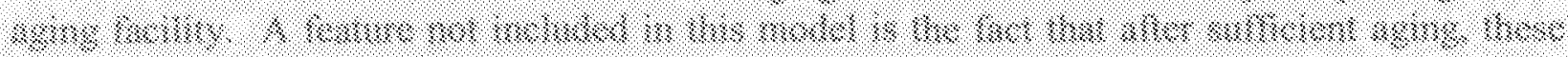

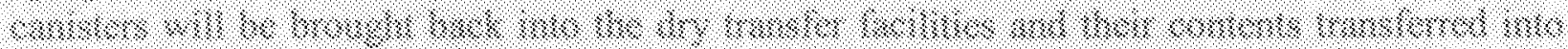

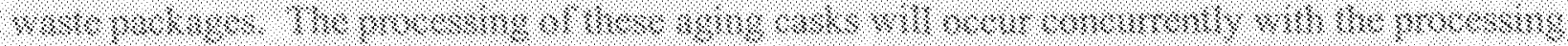

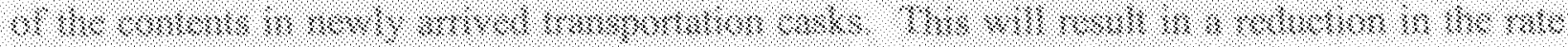

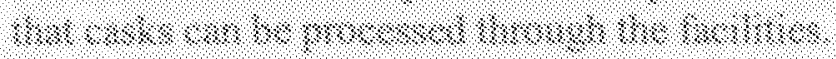

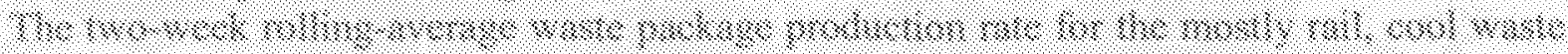

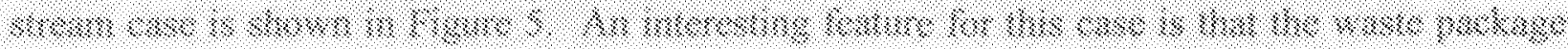




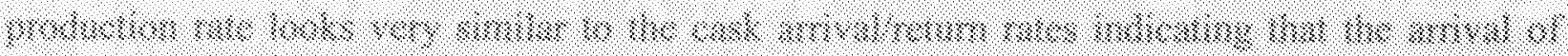

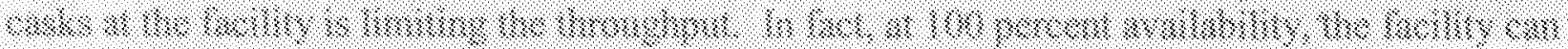

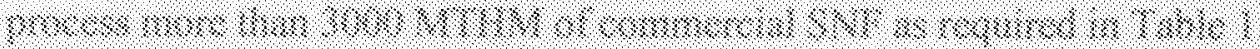

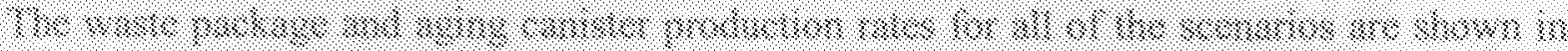

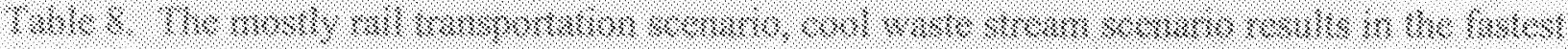

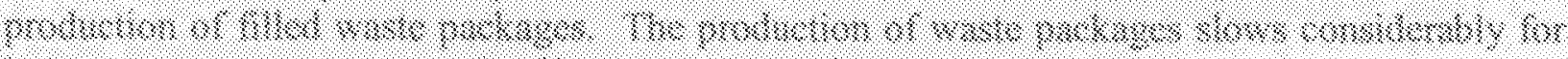

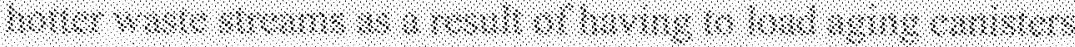

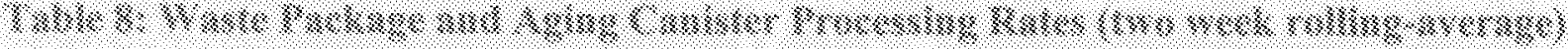

\begin{tabular}{|c|c|c|}
\hline (1) & 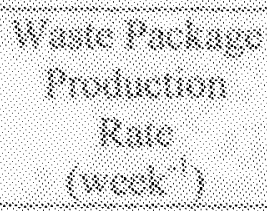 & 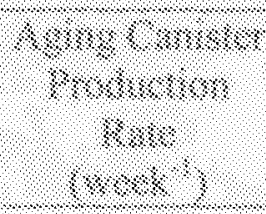 \\
\hline 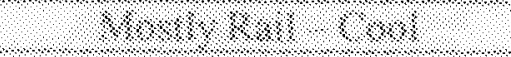 & 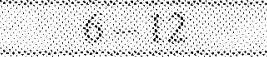 & \\
\hline 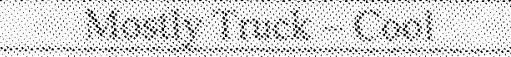 & 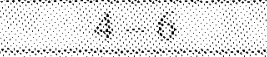 & \\
\hline 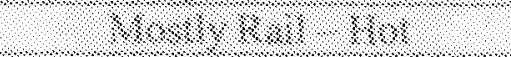 & 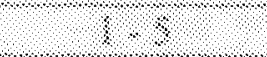 & 1618 \\
\hline 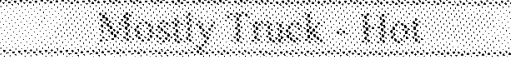 & 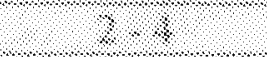 & $1 \% 18$ \\
\hline
\end{tabular}

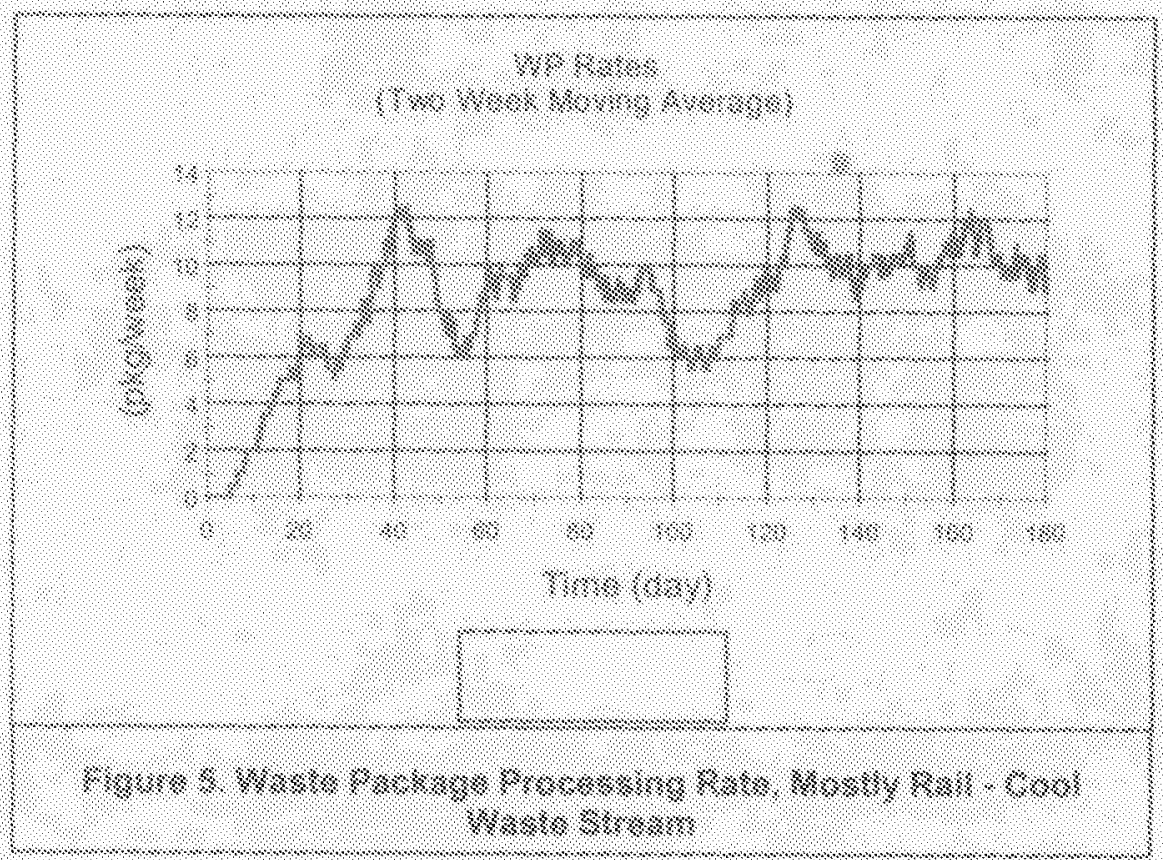

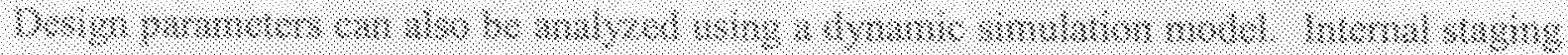

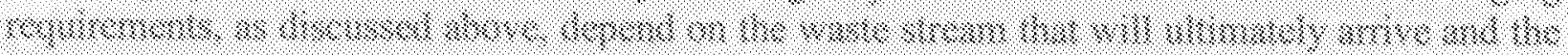

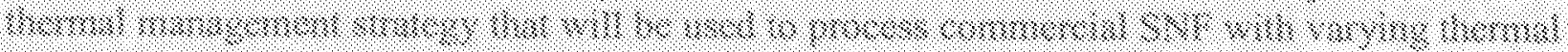

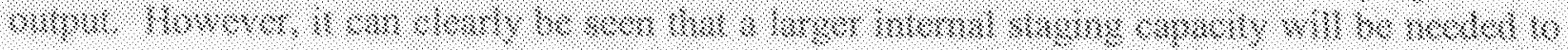




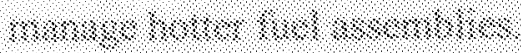

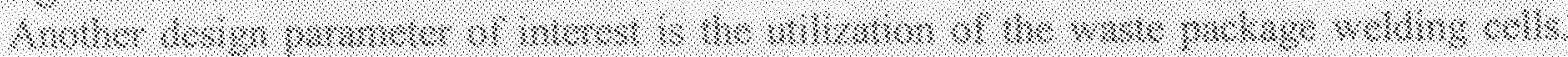

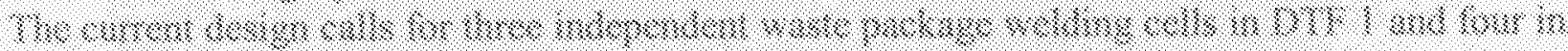

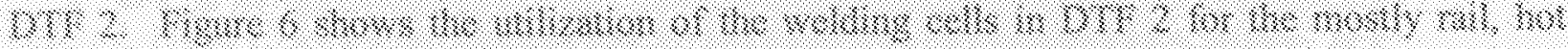

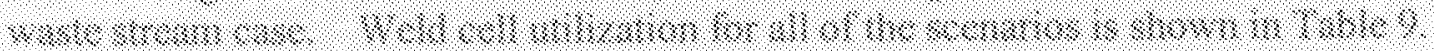

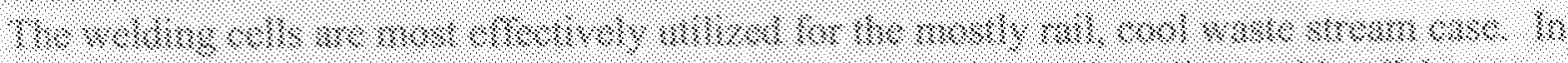

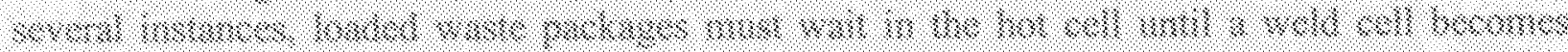

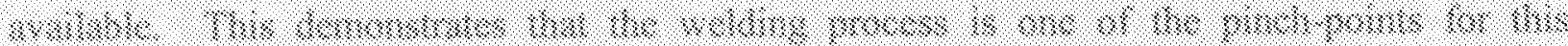

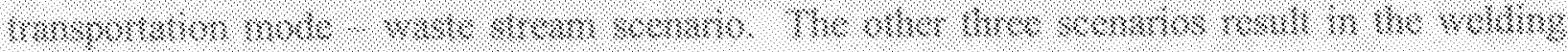

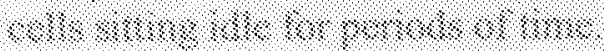

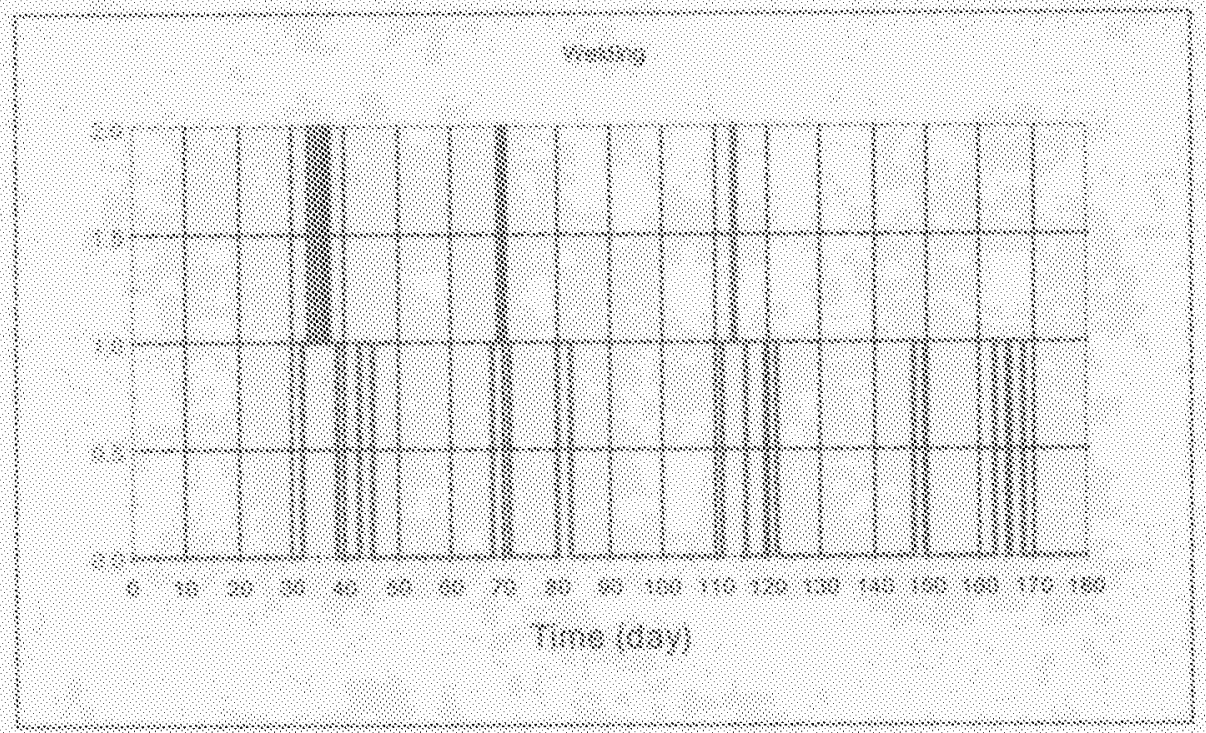

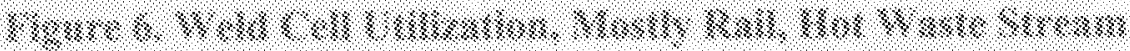

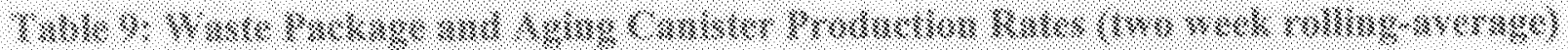

\begin{tabular}{|c|c|c|}
\hline 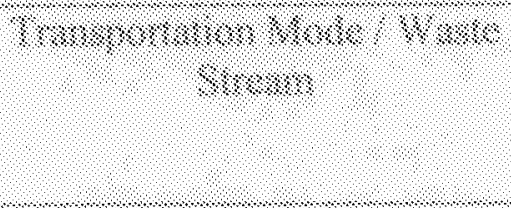 & 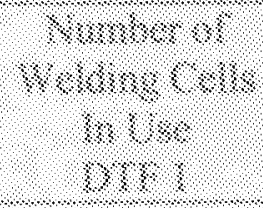 & 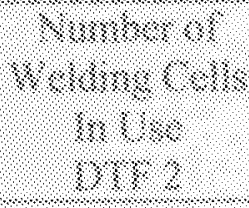 \\
\hline $4: 1 \%: 1.4 \%$ & 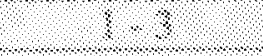 & 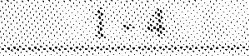 \\
\hline $3 \% 14 \%(1 \%)$ & 1819 & $18: 18$ \\
\hline 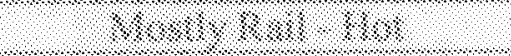 & 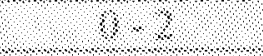 & 1,18 \\
\hline 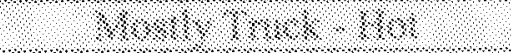 & 4.8 & 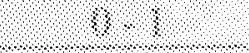 \\
\hline
\end{tabular}




\section{Lessons Learned}

Several lessons learned were revealed as a result of developing the initial dynamic simulation model of the MGR surface facilities. While many of these are specific to the throughput model, many lessons can be applied generically for other model development endeavors.

Highlights of these lessons are listed below:

- The operational logic used in the model has a significant impact on system performance (e.g., waste package production rates, cask return rates). Although experts from various disciplines were consulted in developing the model, different facility operating logic may ultimately be used.

- Process times have a significant effect on system performance. The process times used in this initial model are only estimates. This is appropriate given the early stage of the design of the facilities. As the design advances, these process times should have strong technical bases including detailed analyses and operation experience. Process times can be easily modified as better estimates become available and are confirmed.

- The model results indicate that the ability to process smaller casks through the facilities limits system performance for the mostly truck cask arrival scenario. The surface facilities are much more efficient at processing waste when it arrives in larger rail casks.

- The time required to transfer waste (bare fuel or canisters) in the hot-cell has the most significant impact on system performance.

- The characteristics of the waste stream, in particular the thermal output of the arriving commercial spent nuclear fuel has a significant impact on system performance.

- The thermal management strategy utilized will have a significant impact on system performance.

- Understanding which parameters and variables control system performance and including them in the model allows a quantitative assessment of how they truly affect system performance. This also results in a flexible model that can easily be changed to incorporate new or changing information.

- A top-down approach should be used where models are as simple as possible. This permits the focus to be on overall system performance, rather than focusing on lowerlevel factors. Additional detail can be added based on the results and the availability of additional information.

- The process of evaluating functions, operations, and logic in the development of such a model is of equal benefit as the results it generates. This fosters cross-discipline integration and leads to the increased understanding of system behavior

There are several benefits to developing a dynamic simulation model of such a complex system, including:

- Provides a quantitative tool for estimating system performance,

- Provides an excellent framework to aid in cross-discipline integration,

- Provides a tool to test various operational logic,

- Provides a tool to evaluate potential design changes,

- Provides insights into how a system would need to be operated

- Provides validation of system/subsystem requirements 
Users of such a dynamic simulation model and its results must also take care so as not to encounter pitfalls that include:

- Such a model is only good as the data used as input (i.e., garbage in - garbage out). If the supporting data are of questionable value, then the results themselves are questionable.

- Results generated should be used within their context. The development of such a model requires many assumptions. Not understanding the assumptions beneath the model could cause the results to be used inappropriately and perhaps erroneously.

- Over reliance on model results may lead to shortfalls in the design. Although there are tremendous benefits of using dynamic simulation, it should be viewed as one of several useful tools to aid in the design process.

\section{Acknowledgments}

This work was developed for the U.S. Department of Energy Office of Civilian Radioactive Waste Management under contract DE-AC28-02RW12152.

\section{References}

Hill, R., Nutt, W., Risk Informed Design for Systern Life Cycle, $13^{\text {th }}$ Annual International Symposium Proceedings INCOSE (2003).

U.S. Department of Energy, Civilian Radioactive Waste Management System Requirements Document, DOE/RW-0406, Rev. 5, DCN 5 (2002).

Golder Associates Inc., GoldSim 8.01 (2003).

\section{Biography}

Mr. Sequeira is employed by Booz Allen Hamilton in the position of surface facility design lead for the Management and Technical Support Services contractor team supporting the U.S. Department of Energy Office of Civilian Radioactive Waste Management. He received his B.S. in electrical engineering from California State University of Long Beach in 1986, and his Master's in Engineering from California State Polytechnic University in 1993. He has experience in aerospace electrical system design, system analysis, system requirements, electrical circuits modeling, and nuclear handling design and operations.

Dr. Mark Nutt is employed by Golder Associates Inc. in the position of technical teams coordinator for the Management and Technical Support Services contractor team supporting the U.S. Department of Energy Office of Civilian Radioactive Waste Management. He received B.S., M.S., and Ph.D. degrees in Nuclear Engineering from Iowa State University in 1985, 1989, and 1995. He has experience in nuclear design and the application of probabilistic performance/risk assessment techniques to evaluate the long-term performance of radioactive waste disposal facilities. 